\title{
Organizing, Performing and Presenting Scientific Work in Engineering Education with the Help of Mobile Devices
}

\author{
http://dx.doi.org/10.3991/ijim.v9i4.4726 \\ D. May and $\mathrm{Ph}$. Ossenberg \\ TU Dortmund University, Dortmund, Germany
}

\begin{abstract}
The meaningful use of mobile devices in higher education learning contexts is still underrepresented at German universities. Even if these "new" technologies open up totally new teaching and learning experiences the current use is strongly dominated by simple technology provision. With a special course-designed for engineering studentsthe authors want to change this and go more into the direction of meaningful interaction and collaboration with the help of mobile devices throughout the learning process. The course is developed to give the students the opportunity to use tablet PCs in context of their studies and simultaneously to improve their ability in the field of scientific working processes. Making use of the online tool Evernote supported this aim. This tool allows users to work out and share digital notebooks and with this to organize as well as document a working process. In this case it was used to support a scientific research process from the beginning to the end. As Evernote can be used with an mobile app it easily can be used on tablet PCs. Hence, it supports the course idea of using mobile devices in perfect way. The course itself is divided into four face-to-face meetings and three working phases. By taking part in the course the students go through their own research project with explicit steps-from having a new idea for research to the results' presentation. The meetings are mainly used in order to introduce tools or techniques for research processes. During the working phases the students do their research, create presentations, a poster, and a scientific report. Based on the internal course evaluation and the students' feedback we observed, that the combination of tablet PCs with the Evernote software is a good opportunity to show how mobile devices can be meaningfully integrated into higher engineering education.
\end{abstract}

Index Terms-mobile learning, mobile devices, scientific work, Evernote

\section{INTRODUCTION: IDEA AND GOAL}

This paper and the described course concept are dominated by two different topics. On the one hand the use of mobile devices in higher engineering education or better: mobile learning [1] is focused. On the other hand this work deals with the scientific research process and its presence within engineering education. For both topics the authors found potential for future improvements in higher education and the presented work should lead in this direction.

Mobile devices are daily companions for today's students. Most of them own at least a smartphone or even a tablet PC. Virtually everywhere at the university you can

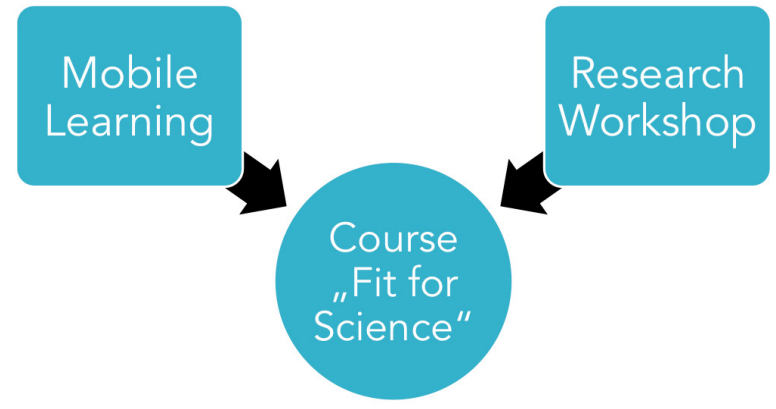

Figure 1. ELLI Working packages contributing to the course concept

see students reading on and texting with their mobile devices. In contrast to that the use of such devices for explicit study purposes is less common in German higher education. That is shown by empiric studies done by the authors over the last two years [2], [3]. The use of smartphones or tablet PCs with the aim to support or even improve the learning experience is seldom. Even if the corresponding pedagogical trend "mobile learning" [1] grew stronger in higher education over the past decades, this process seems to be rather forced by teachers than by the students themselves. This observation was supported by qualitative research in the form of interviews enriching the study results mentioned above.

Another important observation that can be made at many universities at least in Germany is, that even if universities are a place for scientific work and research the concept how research works and what it means to work in a scientific manner are only shown to engineering students but their can seldom experience doing it themselves. In many cases the bachelor thesis is the first scientific artifact that is worked out by the students. This of course has a heavily negative impact on the students' ability to work scientifically and write scientific documents.

In the light of those two observations the authors designed and implemented with "Fit for Science" a special course for engineering students in order to improve (1) their ability to work scientifically, (2) their skills to use mobile devices for collaboration in scientific contexts and (3) their scientific writing skills. The course was firstly implemented in summer 2014 and a second edition was given in the winter term 2014/15. In the summer term 2015 the third edition will take place. From one edition to the next one, the evaluation and research results will im- 
prove the course concept. All the work is done in context of the project "ELLI - Excellent teaching and learning in engineering education". Within this project two working packages are focusing on mobile learning and on a research workshop for students (Fig. 1). Combining these two views was a first step into design process for the presented course. This paper will explain the underlying research concepts as well a preliminary considerations, the course design itself, the students' feedback and planned improvements for the future.

\section{RESEARCH CONCEPT AND PREVIOUS OBSERVATIONS IMPORTANT FOR THE COURSE DESIGN PROCESS}

Just as the presented course "Fit for Science" itself is focusing on the process of scientific research the course design process as well is embedded in an underlying research process, too. This process is oriented towards classical research circles, which exist in nearly every science and are more or less similar in its fundamental steps (see e.g. [4]). In our presented case the basic steps are:

1. Idea for new research,

2. general goal formulation,

3. overview over existing work and connections to prior research,

4. formulation of concrete research question,

5. research action,

6. reflection on results, and

7. implementation of improvements or start of new research circle.

In order to go through this research steps and work out a course concept at the same time we had to synchronize both processes. Figure 2 shows how this worked out in practice.

\section{A. Goal formulation}

As this paper's aim is mainly to present the developed course concept and the students feedback, the focus will lay on these two aspects. They represent the last five steps of our research process. However, the previous considerations during step one to three are important to understand the whole process. Hence they will be explained shortly in the following. The main focus will lay on the effective usage of mobile devices in educational engineering contexts, which reflects the basic idea. Our general goal for our research was to improve engineering education by integrating such devices into educational settings with a main focus on collaborative learning processes. In the following we will give a short overview over existing work. In addition to that we will explain how this work is connected to prior work at our institution.

\section{B. Overview}

After defining the general goal for the design process we look in the following at existing work in the field of learning with mobile devices and describe the environment in which we implement the course concept.

1) Use of mobile devices in higher engineering education

Using mobile devices is completely normal in the present time. The release of new smartphones or tablet PCs from the company with the apple in its logo is regularly an exceptional period for a whole industry sector. Hence, our idea and goal for the presented work was to bring mobile devices more into educational settings in higher engineering education. Or focus in this context was to put on the support of communicative and co-operative process with the help of mobile devices.

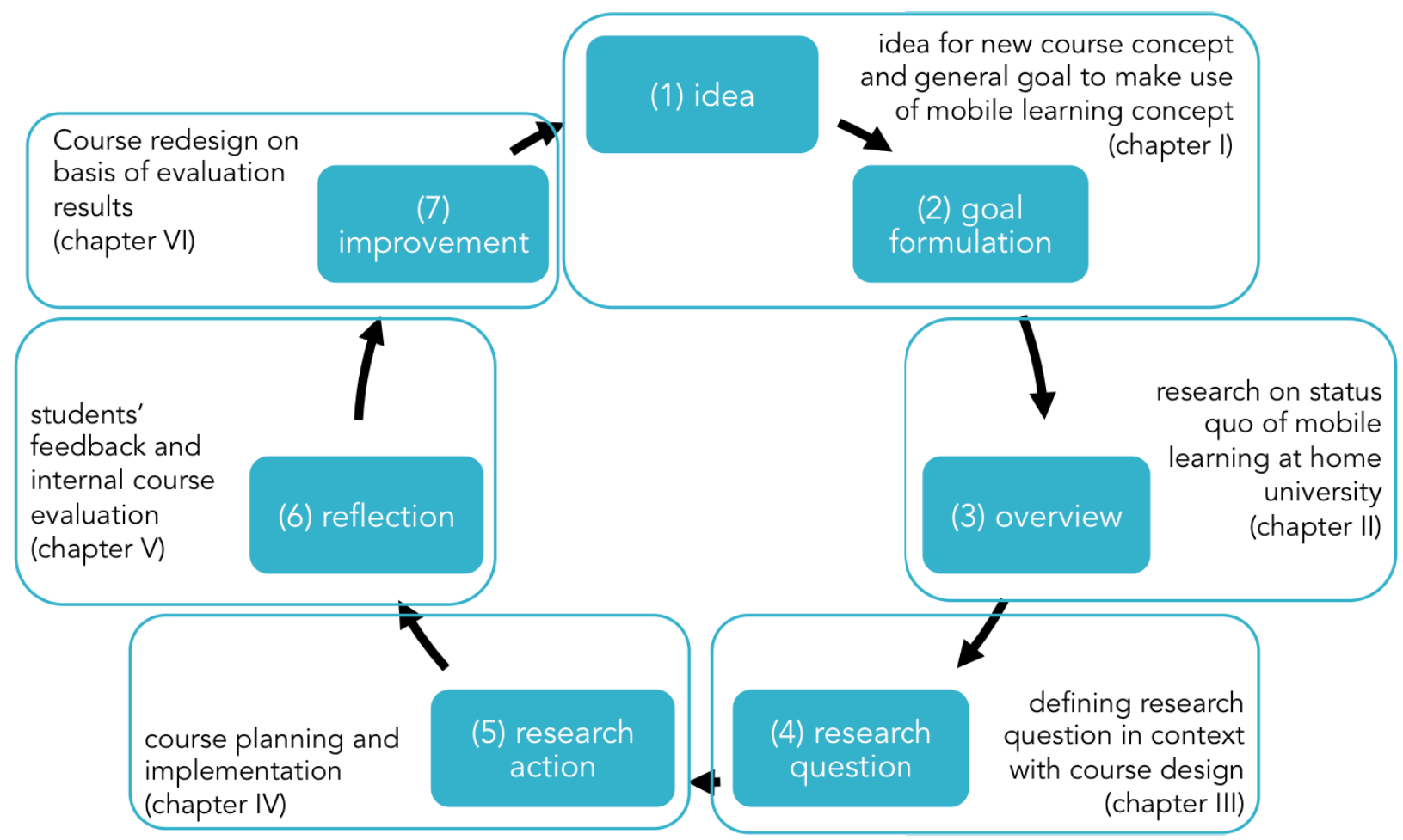

Figure 2. Synchronized Research Circle and Course Design Process 
The strong development towards mobile devices also has an impact on universities and higher education. Whereas the universities develop special apps to make the students' life easier (these apps for example contain campus maps, timetables or refectory plans; e.g. RUB App at the Ruhr University Bochum [5]) the field of "mobile learning' as a new learning scenario emerged at the beginning of the nineties' [1]. Since then, this area of research steadily grew so that more and more educators are presently working on the improvement of the students' learning process with the help of mobile devices and conduct connected research. [6] for example recently published a chapter on 'iPad didactics' speaking about "[...] new forms of pedagogical concepts for education like transformative learning and complex learning supported by mobile ICT [information and communication technologies] and interactive media and learning (IML)" [6]. In general the company 'Apple' seems to be highly interested in the education sector as they are offensively promoting their technology for curriculum design, assessment and teaching [7]. Moreover a growing number of publications on mobile learning can be observed on engineering education conferences. For example on the last 'Frontiers in Education Conference 2014" in Madrid more than fifteen papers presented work in context with mobile learning [8]. Most of them deal with the use of mobile devices directly in class or to support the learning process during a course. Nevertheless such approaches remain exceptions in the light of the total amount of engineering courses given all over the world every day.

In addition to that there is only little data on the actual use of mobile devices for study purposes outside of such exceptional approaches. Moreover such approaches seem to be more present in the Scandinavian and the AngloAmerican regions. Hence, for us the question was: What is the status quo on mobile learning solutions at German universities in engineering education? It was important for us not only taking the communities' discussion throughout the world into consideration but also having a strong focus on the German educational sector which may show some shortcomings in the implementation of mobile learning in comparison to other regions. Therefore an empirical study with questionnaires was done in 2013 to find out what the students really use [2], [3]. The results show, among others, that firstly nearly every student owns at least a smartphone and around a quarter of them do own a tablet PC, too. That was not surprising at all. What indeed was surprising is that secondly most of the students seldom or never use their mobile device for study purposes. This is clearly shown by the answers on the questions "How often do you use your mobile device (smartphone and tablet) or mobile apps for study purposes?" and "How often have you encouraged by your teacher to use your mobile device for study purposes?":

"The results show that $23,4 \%$ of the students use their smartphone never or very seldom in context of learning, whereas $63,9 \%$ do this often or very often $(12,7 \%$ use it from time to time). The same question asking for tablet computers disclosed totally contrary results: $69 \%$ use their tablet never or seldom and only $26 \%$ use it often or very often (in context with studies). [...] The last question in this context was, how often the students use mobile apps for learning. The answers reveal that the use of apps explicitly for learning is not very common yet. Only 7,2\% of the students use mobile apps often or very often for learning, but $84,7 \%$ use it seldom or never. [...] An additional question asked for the encouragement to use mobile devices during a course. So the students were asked: "Have you been encouraged to use your mobile device during the course? If yes, for what kind of purpose?" The results exposure that only $22,6 \%$ of the students have been asked often or very often to use their devices in context with a course. In most of these cases (65\%) those who were asked to do so, were requested to use them in order to take part at any kind of polling. Polling means in this situation that the teacher asks a question in course-context and the students had to use their device and special software to answer it. The answers are then discussed in the audience. [...] Dividing the apps by the purpose they are used for, 7 different clusters could be identified. 109 (31\%) of the named apps serve as any kind of database, 79 (22\%) are used for the organization of learning and 47 (13\%) for any kind of application and testing. 40 (11\%) apps are language dictionaries, 30 (8\%) help to make notes or edit documents and 20 (6\%) are used for cloud computing. Finally 32 (9\%) apps could not be allocated to any cluster. Hence they were summarized under 'others'." [3]

Interviews that accompanied the questionnaires supported these observations and made obvious that many students simply do not know how to use their devices meaningfully for learning and co-operation. Hence, a major lack can be seen in the students' inaptitude to work together using their mobile devices for study, or better, for learning purposes. That was one reason to design the course "Fit for Science" with a special focus on mobile devices and their options to support collaborative working and learning processes.

With the Research Workshop at TU Dortmund University we had a perfect setting for this work in order to develop and implement the course. Therefore this setting will be described shortly in the following.

\section{2) Excursus: Research workshop for students}

The main idea behind the Research Workshop is to synchronize students learning with the typical steps of a research process [9]. To reach this, we offer various arrangements to the students in a special seminar room, which is furnished to support learning and working in groups as best as possible (Fig. 3). In short extracurricular courses students can improve their key qualifications in 'scientific working' or 'writing with LaTeX'. The course "Fit for Science" is another course example we are offering in the Research Workshop. Last but not least we offer the room itself either for learning or for working on own research projects. During the semester, the seminar room has regular opening hours. Students for example can use experimentation kits like 'LEGO Mindstorms' to conduct small experiments, called FLExperiments [10]. To encourage and support the students' investigation we provide small scripts including hypothesis and research questions. During the opening hours students can come in and ask for assistance of a qualified tutor, who can give advice e.g. in fields of 'scientific working' or 'time management'. The Course "Fit for Science" combines both approaches from above. It takes place in context with the Research Workshop and focuses besides the topic of scientific working the meaningful use of mobile devices. 


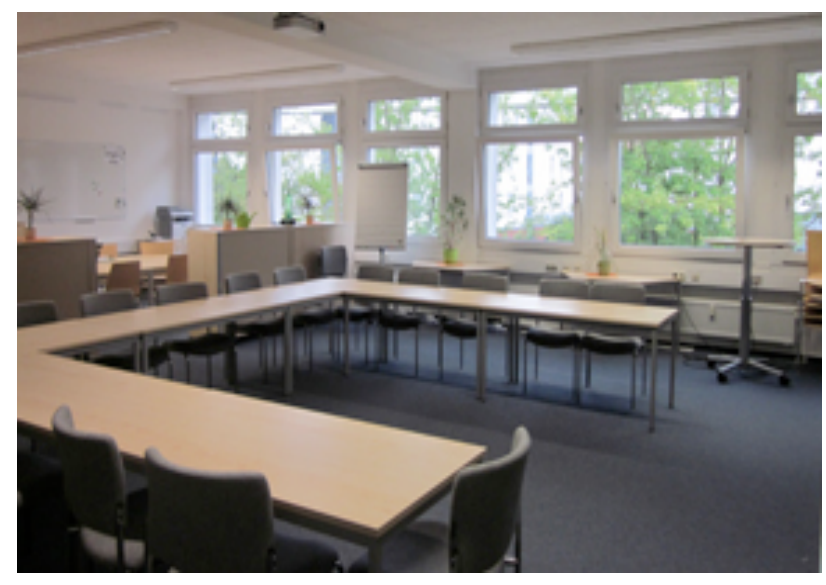

Figure 3. Research Workshop at TU Dortmund University

\section{RESEARCH QUESTION}

Based on the overview on existing research, the observations and the connections within the ELLI projects explained above we were able to formulate the explicit research questions for our work. These were:

- How can tablet PCs support collaboration in research processes?

- How can the results of the first question be applied by designing courses in higher education?

In order to answer these research questions we took into account the general overview explained in II and started with the research action. That means that the course planning and implementation was an essential part for us to answer these questions. This research action was later in validated and supported by the internal course evaluation and the students' final course feedback.

\section{RESEARCH ACtion: MethodologicAL CONSIDERATIONS AND COURSE DESIGN PROCESS}

\section{A. Methodological Considerations}

As we wanted to conduct research on the use of mobile devices and simultaneously develop a course concept with the help of such devices we found for the methodological basis the "Design-Based-Research" (DBR) concept as a highly fitting concept to guide us through this process. DBR aims on the development of technology enhanced learning scenarios on the one hand and at the same time it aims on systematic research on these scenarios on the other hand [11], [12]. Hence, the DBR approach is " $a$ systematic but flexible methodology aimed to improve educational practice through iterative analysis, design, development, and implementation, based on collaboration among researchers and practitioners in real-world settings, and leading to contextually sensitive design principles and theories" [13].

Using this methodology gives us the opportunity for being at the same time researchers and teachers. In addition to that DBR bases on a two cyclic phases [11]:

(a) Phase of action: intervention, design, implementation (see section IV)

(b) Phase of analysis: reflection of implemented intervention (see section V)
That these phases are meant to be cyclical means that after the evaluation a second phase of interaction starts, which is again evaluated in next step.

Having all this in mind we were able go ahead in our own research cycle. 'Planning the research action' and 'research action' in our case this meant to plan and give the course itself.

In order to give an overview on how we introduced the mobile devices in the course we will firstly explain the course concept in the following. After that we will explain the students feedback, which in our case goes hand in hand with step (6) 'reflection on results'.

We planned the course "Fit for Science" for the first time for the summer semester 2014. As explained above our overall goal was to design a course concept, which at the same time teaches how scientific research processes are carried out and how to use mobile devices for those research processes in a collaborative manner. In the following we will explain how the work was designed finally. We will begin with the intended learning outcomes, explain afterwards the organizational considerations and finally the instructional activities will be laid out.

\section{$B$. Intended learning outcomes}

In order to plan the instructional activities it was important to define the intended learning outcomes first. These outcomes are directly deduced from our overall goal. However, they explain the goal more in detail andthat is the most important aspect- they can be used to openly reveal to the students what they are expected to do throughout the course. Following the intended learning outcomes, at the end of the course the students should be able to...

- ...conduct own research processes in a group,

- ...organize and document scientific work with the help of new collaborative media and mobile devices,

- ...present results of scientific work with different media, and

- ...write a short scientific paper on basis of common scientific norms with the help of adequate tools.

\section{Organizational considerations \& course schedule}

Looking from the general organizational perspective the course can be split into three major thematic parts:

- Organization of scientific work

- Methods of scientific work with focus on literature search

\section{- Presentation of scientific work and results}

These major parts are designed so that the students were able to carry out an own research process. Furthermore looking at the detailed schedule the course consists of four full-day classroom sessions at the university. For these sessions all participants come together. This is accompanied by three working phases in between the meetings. During these working phases most of the course's work is carried out. Hence, the meetings mainly serve for presenting achieved results and preparing the students for the next working phase.

As the general course goal indicates the research process with its different parts is the overall orientation for the course design. Hence, the "Fit for Science" course 
schedule itself reflects a simplified research process with the following six steps:

- Starting for new research on specific topic,

- Gaining an overview and searching for existing work,

- Confining research question,

- Carrying out detailed literature research,

- Answering research question on basis of literature, and finally,

- Presenting the results in written and oral form.

Fig. 4 shows the course concept with all its different meetings and steps. It furthermore explains how on the one hand the three major phases are distributed among the four in-class sessions and the three working phases. On the other hand it explains how this course schedule is synchronized with the research steps shown above.

For the whole course the student group is split into smaller teams of three to four students. Each team has to perform its own research and go through the whole process once. As the course concept heavily bases on the use of tablet PCs the students either could use their own ones or borrow one from the university for the whole course time. Most of the instructional activities are designed so that they can be carried out with the help of tablet PCs. Based on our own experiences we chose the online tool 'Evernote' [14] as the fitting tool to the support the students' collaboration among each other and organize the working process. Evernote is an online workspace that allows writing notes, collecting search results, finding data and presenting work in one digital notebook, which can be shared among the team members. Additionally we chose the online tool 'Mindmeister' [15], which serves for work- ing out digital mind-maps, which also can be shared among different team members. In the following we will briefly explain each course parts and its meeting. Furthermore the instructional activities and the contextualized use of tablet PCs will be laid out.

\section{Course parts \& instructional avctivites}

\section{1) First part: Organization of scientific work}

The first major course part equals with the first meeting. In this first part the focus lies on the organization of the research processes. Within this step the course concept with its intended learning outcomes is presented to the students. In addition to that they have to organize their working process in the group, and make themselves familiar with basics of scientific work in general. All of this is done during the first meeting by a mixture of several instructional methods. For example the general process of scientific work is on the one hand presented to the students but on the other hand additionally worked out more in depth by themselves with the help of several group tasks. In order to not being too theoretically at this early point the students group already choose their topic of interest for the following research process. As the topic in this case is just a means to an end and the process itself is more in focus, the groups can choose their own favorite topic. We as lecturers just give possible topics in order to help if the students can not decide. For example in the 2014 summer term's edition of this course the groups finally worked on the topics "e-mobility", "fuel cell technology", "industry 4.0", and "resource efficiency in production processes" and during the following winter term's edition the research work was focused on "e-mobility" and "mobility concepts in mega cities". At this point the topics are defined very broadly as one of the students task

course schedule of "Fit for Science"

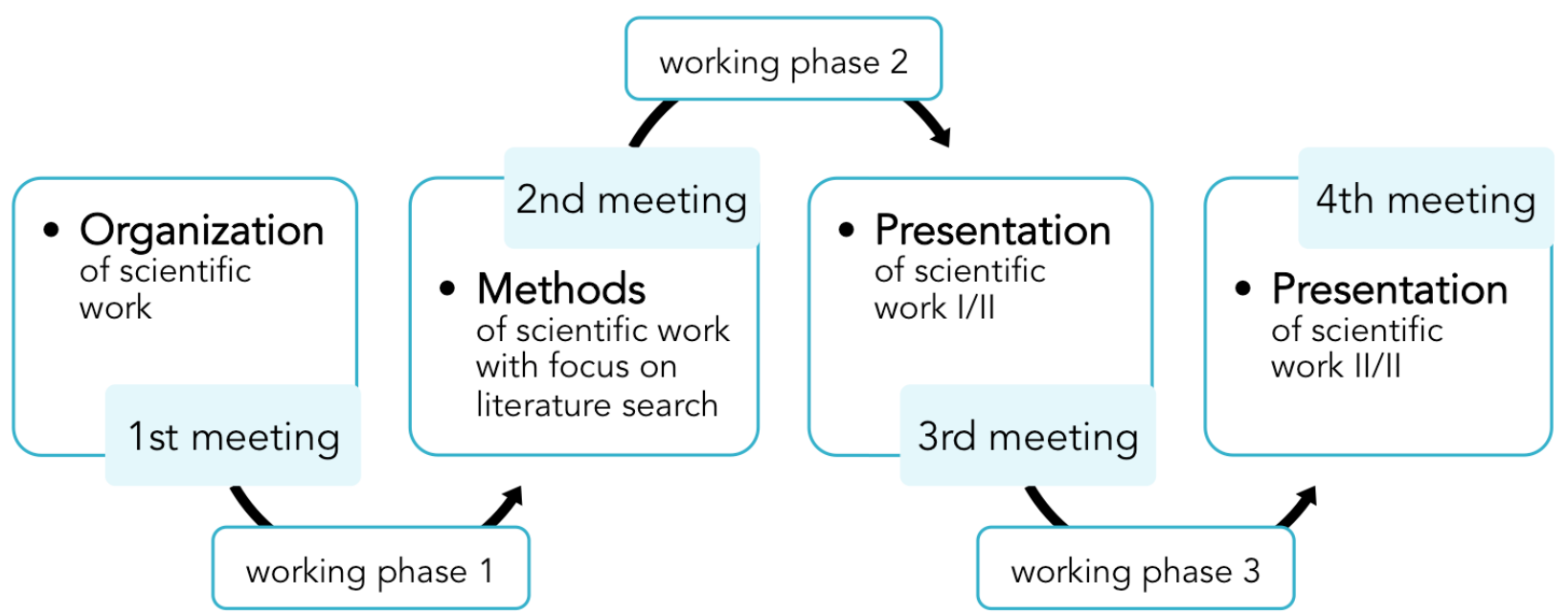

research process followed within "Fit for Science"

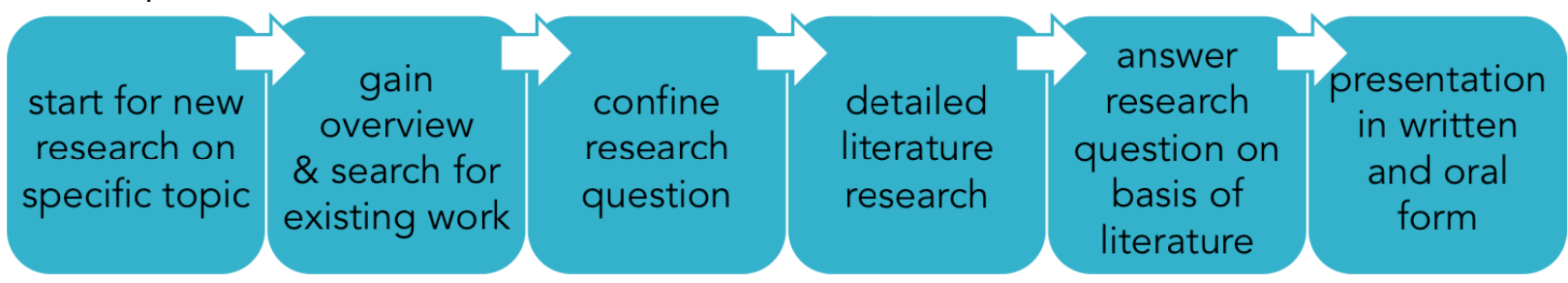

Figure 4. Course schedule and followed research process 
for later on is to narrow the topic so that a concrete research question can be formulated and an effective literature research can be carried out. The task for the first working phase is to gain an overview of the topic and search for existing work. During the phase they additionally develop first ideas for the research question.

In order to support the group work the tools Evernote and Mindmeister are introduced at this point und have to be used by the students from the first meeting on. Both are easily usable with tablet PCs so that their use perfectly fits to our course goals. The advantage of those tools for the working processes is that with both of them work artifacts can be jointly produced even if the groups do not physically meet. Hence, the idea of mobility and flexibility that lies beyond the concept of mobile learning is supported here [16]. To be more concrete, the students have to use Evernote to work out a shared notebook, in which their work processes are organized and documented. Moreover they have to use Mindmeister in order to work out a mind map on their topic of research. This mind map should reflect the overview and the search results on existing work in context with their topic. The development of the mind map is the main task for the first working phase.

2) Second part: methods of scientific work with focus on literature search

At the beginning of the second phase (and so at the beginning of the second face-to-face meeting) the students present their mind map to the rest of the class. With this result they can start in the following research steps. Guided by several detailed methodological steps the students define their explicit research question and present it to the group. At this point it is important that the lecturer and the rest of the course carefully scrutinize the formulated research question. As this question will guide the students during the following research it is necessary that the question is very detailed. The students have to try to answer this question only on basis of a literature search of some weeks and have to write a scientific paper of only seven pages on this later on. Hence, a very board question does not help in this context This must be understood by the students, as they tend to formulate broad questions. In a next step basic concepts and explicit methods for literature research come into focus. This includes concepts to find relevant texts and to organize the emerging literature database. For both aspects additional tools like online library databases or 'Citavi' (a tool for literature administration and knowledge organization [17]) are presented and the students learn their usage guided by explicit tasks.

An additional but very essential topic of the second meeting is the underlying idea and importance of using, respecting and listing references during scientific work. As the students start with their scientific paper after this meeting different concepts of referencing sources in papers are discussed, too. Moreover the text type "scientific paper" with its important parts and basic rules for writing such a text are discussed. With this knowledge and skills the research groups start into the second working phase, in which they firstly conduct a detailed literature research in order to answer their research question and secondly start with the writing process.

\section{3) Third part: Presentation of scientific work}

In the final part of "Fit for Science", which covers the last two meetings, the presentation of scientific work comes into focus. In order to show the diversity of pre- senting methods different options are discussed as well as used by the students. This starts with the presentation of their current working process and first research results using the Evernote tool. We explicitly ask the student to use this in order to have them experiencing several options to present working results apart from the classical PowerPoint presentation. Evernote has a special presentation mode, which allows the students to easily present the working process using the tablet PC. After that the course focuses on the presentation of scientific work with the help of the formats presentation slides and scientific posters, as those two formats are very common in the scientific community. During several assignments the students acquire characteristics of good talks, presentations and posters. That means that all these publication forms are discussed in course regarding questions like "What are good and bad examples?", "What are the differences in the use of texts, slides and posters?" and "What is the impact of the different aspects for the design?".

At this point the students start into the third working phase, which is mainly used for finally answering the research question based on the found literature. The results should be prepared for the final meeting in three different ways. Firstly a short presentation with slides should be given. This should be enriched with a scientific poster summing up the results. Additionally and as mentioned above the students have to work out a scientific paper and hand it in. A feedback on their presentation and the poster is given by the whole group and by the course instructors. The scientific papers is only rated by the instructors. With this phase of presenting the work the course ends after the fourth meeting.

\section{REFLECTION: COURSE EVALUATION AND STUDENTS' FEEDBACK}

16 students took part in this first edition and 7 students joined the second edition (for the third edition, which will take place, during the publication process of this paper, again 16 signed up). In order to enrich our own course valuation and to receive a proper student feedback on the course, they had to write a final reflective paper and fill out questionnaires $(\mathrm{n} 1=13, \mathrm{n} 2=7$; mainly asking the students to rate statements using a five point scale from "I fully agree" to "I do not agree"). The feedback mainly based on two central approaches: On a general feedback and on the digital instructional resources used during the course.

\section{A. General feedback on the course}

The general feedback from the students was very positive. They stated that they liked the course in its current form and did improve their abilities to conduct own research processes. As explained in the introduction, working scientifically and writing scientific papers is seldom taught in general engineering curricula. The students recognize this, too. One question in the questionnaire directly addressed this observation. In that context 7 students agreed and even 12 students fully agreed with the statement that they visit the course to learn something about methodological concepts of scientific work (students from both editions were taken into account). Hence, they are thankful for such opportunities. This is even more visible in additional written student statements like "In general I learned a lot in this course and the atmosphere was continuous comfortable". 
The most frequently mentioned point of criticism is that the students did not like the given software Evernote (parts of them would prefer MS OneNote). Another point of interest is the average time the students use the tablet PCs. The statements lead to the conclusion that they quite seldom use their tablet PCs in context of actual learning processes but instead for communication and online research 10 statements support this conclusion, whereas 6 students use their tablet PC frequently.

Asking for the most important course topic especially the part about literature research and reference managements systems was voted very positive. We additionally were very pleased that 14 students full agreed with the statement: "I was encouraged to think about practical application of theoretical knowledge".

\section{B. Feedback on instructional ressources}

The other aspect is about the usage of instructional resources within the course. Hence, we analyzed the reflective papers in a first step with the intention to find out which programs students mentioned having used during the course. With this we want to find out which activities were done with desktop computers and the tablet PCs on the one hand and on the other hand we want to identify additional programs or apps they used. Therefore we counted the mentioned programmed and identified categories corresponding with explicit activities. At this point we did not distinguish between activities done with the help of a desktop computer or a tablet PC. Altogether we have analyzed 18 reflective papers.

The coding of the reflective papers led to 6 definable categories and 1 category of 'others'. The final categories are (sorted in descending order):

- Scratch Pad (e.g. Evernote)

- File Hosting Service (e.g. Dropbox)

- Instant Messaging (e.g. Facebook messenger)

- Classic Document Processing (e.g.Word)

- Mind Mapping Tool (e.g. Mindmeister)

- Reference Management (e.g. Citavi)

It is not surprising that Scratch Pad is the most often mentioned category as this category is deeply connected to the requirements we defined by designing the course, e.g. by promoting Evernote as the program for collaborative work processes. The category 'others' includes for example apps like YouTube but also Doodle (tool to find a date for appointments). All groups used a File Hosting Service like Google Drive or Dropbox especially when writing the scientific paper. Some groups used instant massaging to communicate efficiently. Especially during the second edition quite a number of students used the Evernote Work-Chat to communicate, as the app designers introduced this opportunity just before the course started. Mind Mapping Tools are only mentioned in context with the first course phase. Even if all the students mentioned to have used a reference management system like Citavi at least once in context with the course the scientific papers clearly showed that not all groups have used that properly. This was one aspect we especially focused on during the second course edition and it will be an important aspect we will have to keep our focus on during the next editions.

However our question not only was, which programs the students used in general but even more important was to find out how they finally used the tablet PCs. Even if some of the students said, that they had to change to a normal PC for explicit tasks (for example for longer writing processes for the paper), they were positively surprised by the options tablet PCs and connected apps offer. By analyzing the reflective paper in a second step we identified categories of activities students did with their tablet PCs in context with the course activities. Finally we were able to clearly define the following eight different categories (again sorted in descending order; supplemented by a category 'others' and a category for 'leisure activities'):

- Organize and document work processes (e.g. with Evernote)

- Search for information (e.g. with library databases)

- View and edit PDF files (e.g. with PDF viewer)

- Create mind maps (e.g. with Mindmeister)

- Share and synchronize files (e.g. Dropbox)

- Communicate (e.g. with Skype)

- Create documents (e.g. with www.titanpad.com)

- Time management (e.g. calendar app)

Because of the special course design, it was not surprising that the most frequently mentioned activity is to organize and document work processes with Evernote. Following the course requirements (use information from library databases to write a scientific paper) the another frequently mentioned activity was to find course relevant information in databases and on websites by using the tablet PCs. Additionally most of the students used the tablet PCs to view and edit PDF files, e.g. to find and analyze information or make notes on slides during lectures (some of the answers indicated that this usage was not limited to our course context but the students even used the borrowed tablets in other courses for this purpose). Unfortunately the students created mind maps only because they had to present one in the second meeting. However they have created this mind maps by using the tablet PCs and with the advised application. The ability to share and synchronize files between desktop computers and tablet PC using explicit tools like Dropbox is another good opportunity the students see and made use of. With this they always have relevant documents for the working processes at the hand, no matter which device they are using at the very moment. Students reported that the tablet PCs was seldom used for pure communication purposes and in this context mainly replaced by the smartphone. Those who did use the tablet PC for communication mainly did this with Skype or any mailing application. Although most of the students finished up writing the paper at a desktop PC and not using the tablet PC for creating longer documents, 5 of them students even did this task with the help of their mobile device. In this case they made use of online writing tools like www.titanpad.com, which allows several users to synchronously write in one document at the same time. Last but not least 4 students reported that they use their tablet PC to organize their time and used a special calendar app for that.

At this point we will finish with the overview on the course evaluation and will change over to the future plans with this concept. 


\section{IMPROVEMENT: CONCLUSION AND FUTURE PLANS}

In context with this research we formulated the following research questions:

- How can tablet PCs support collaboration in research processes?

- How can the results of the first question be applied by designing courses in higher education?

In order to answer these two questions we designed and implemented a special course concept, which heavily relied on the use of mobile devices in combination with several tool; mainly Evernote. From our perspective this combination is a very good opportunity in order to meaningfully integrate mobile devices into the teaching and learning process. The evaluation findings support our assumption. The students successfully used this tool and the device in order to organize and document their research process, which in short means they did collaborate with it even if they had to get used to it first. It is obvious that tablet PCs itself do not support collaboration but they need to be integrated in context with adequate application. This is what we productively did with this course.

The course has been implemented only twice up to this moment. By the time of the publication a third round will be running. For the coming courses some adjustments will be done, which are based on the evaluation findings. For example the scientific paper showed clearly that most of the students really struggle with the writing process. When questioned, most of the students said that this was the first longer paper they had to write after finishing school. Hence, a special focus will be laid on the scientific writing process.

Nevertheless the course will become a part of the Research Workshop course program. Hence, it will be taught two times a year and continuously improved with every edition. With this the evaluation and the research methodologies will be further developed, too. That means that we will be able to get more and more meaningful data on the use of mobile devices and advance the research findings on that. In addition to that this course will also be a place in which new ideas in context with the use of mobile devices in teaching can be tested. Successful approaches will be then transferred to other engineering classes.

\section{REFERENCES}

[1] A. Kukulska-Hulme and J. Traxler, Mobile learning: A handbook for educators and trainers. Milton Park and New York: Routlegde and Taylor \& Francis Group, 2005.

[2] K. Schuster, K. Thöing, D. May, K. Lensing, M. Grosch, A. Richert, A. E. Tekkaya, M. Peterman, and Jeschke S, "Status Quo of Media Usage and Mobile Learning in Engineering Education, präsentation on the ECEL Conference 2014, Copenhagen, Denmark, not published yet,"

[3] D. May, K. Lensing, A. E. Tekkaya, M. Grosch, U. Berbuir, and M. Peterman, "What students use - Results of a survey on Media Usage among Engineering Students," in Proceedings of 2014 Frontiers in Education Conference "Opening Doors to Innovation and Internationalization in Engineering Education", 2014.

[4] T. Jungmanm, "Forschendes Lernen im Logistikstuidum: Systemaitische Entwicklung, Implementierung und emprirische Eval- uation einers hochschuldidaktischen Modells am Beispiele des Projektmanagemnts," doctoral dissertation, TU Dortmund University, Dortmund, 2011.

[5] RUB mobile. Available: http://www.ruhr-uni-bochum.de/mobile/ (2014, Nov. 16).

[6] I. Jahnke and S. Kumar, "iPad-Didactics - Didactical Designs for iPad-classrooms: Experiences from Danish Schools and a Swedish University," in The New Landscape of Mobile Learning: Redesigning Education in an App-based World, C. Miller and A. Doering, Eds.: Routledge publisher.

[7] Apple Inc, Curriculum, Assessment, and Teaching Tools for iPad. Available:

https://www.apple.com/education/docs/Curriculum_Assessment Teaching_Tools_for_iPad_8-14.pdf (2014, Nov. 16).

[8] IEEE, Ed, Proceedings of 2014 Frontiers in Education Conference "Opening Doors to Innovation and Internationalization in Engineering Education", 2014.

[9] T. Jungmann and P. Ossenberg, "Research Workshop in Engineering Education: Draft of new Learning," in Proceedings of the 2014 IEEE Global Engineering Education Conference (EDUCON), 2014, pp. 83-87. http://dx.doi.org/10.1109/EDUCON.2014.6826072

[10] P. Ossenberg and T. Jungmann, "Experimentation in a Research Workshop: A Peer-Learning Approach as a First Step to Scientific Competence," International Journal of Engineering Pedagogy (iJEP), vol. 3, no. 3, pp. 27-31, 2013. http://dx.doi.org/10.3991/ijep.v3iS3.2748

[11] I. Jahnke, C. Terkowsky, C. Burkhardt, U. Dirksen, M. Heiner, J. Wildt, and A. E. Tekkaya, "Experimentierendes Lernen entwerfen - eLearning mit Design-based Research," in E-Learning: Lernen im digitalen Zeitalter, N. Apostolopoulos, H. Hoffmann, and Mansmann, V. \& Schwill, A, Eds, Münster: Waxmann, 2009, pp. 279-290.

[12] T. Reeves, J. Herrington, and R. Oliver, "Design research: A socially responsible approach to instructional technology research in higher education," Journal of Computing in Higher Education, vol. 16, pp. 97-116, 2005. http://dx.doi.org/10.1007/BF02961476

[13] F. Wang and M. J. Hannafin, "Design-based research and technology-enhanced learning environments," Educational Technology Research and Development, vol. 53, no. 4, pp. 5-23, 2005. http://dx.doi.org/10.1007/BF02504682

[14] Evernote, The workspace for your life's work. Available: www.evernote.com (2014, Nov. 16).

[15] Mindmeister, Mind Mapping Software - Create Mind Maps online. Available: www.mindmeister.com (2014, Nov. 16).

[16] C. Quinn, "mLearning: mobile, wireless, in-your-pocket learning," LineZine, 2000.

[17] Citavi, Organize your knowledge. Reference management, knowledge organization, and task planning. Available: www.citavi.com (2014, Nov. 16).

\section{AUTHORS}

D. May is with the Center for Higher Education at TU Dortmund University, 44227 Dortmund, NRW, Germany (e-mail: dominik.may@tu-dortmund.de).

P. Ossenberg is with the Center for Higher Education at TU Dortmund University, 44227 Dortmund, NRW, Germany (e-mail: philipp.ossenberg@tu-dortmund.de).

This article is an extended and modified version of a paper presented at the EDUCON2014 conference held at the Military Museum and Cultural Center, Harbiye, Istanbul, Turkey, 3-5 April 2014. This work was supported in part by the German Federal Ministry of Education and Research in context with the project "ELLI". Submitted 15 May 2015. Published as submitted by the authors 20 August 2015. 